\title{
Current plastics pollution threats due to COVID-19 and its possible mitigation techniques: a waste-to-energy conversion via Pyrolysis
}

Tadele Assefa Aragaw ${ }^{1 *}$ (D) and Bassazin Ayalew Mekonnen ${ }^{1,2^{*}}$

\begin{abstract}
Background: The extensive use and production of PPE, and disposal in the COVID-19 pandemic increases the plastic wastes arise environmental threats. Roughly, 129 billion face masks and 65 billion plastic gloves every month are used and disposed of on the globe. The study aims to identify the polymer type of face masks and gloves and sustainable plastic waste management options.

Results: The identification of polymers, which can help for fuel conversion alternatives, was confirmed by FTIR and TGA/DTA analysis and confirms that the polymeric categories fit for the intended purpose. Moreover, the handling technique for upcycling and the environmental impacts of the medical face mask and glove were discussed. The FTIR result revealed that face masks and gloves are polypropylene and PVC thermoplastic polymer, respectively and they can be easily transformed to fuel energy via pyrolysis. The endothermic peaks around $431{ }^{\circ} \mathrm{C}$ for medical glove and $175^{\circ} \mathrm{C}$ for surgical is observed tells that the melting point of the PVC and polypropylene of plastic polymers, respectively. The pyrolysis of the face mask and glove was carried out in a closed reactor at $400{ }^{\circ} \mathrm{C}$ for $1 \mathrm{~h}$. Conferring to lab-scale processes, liquid, and wax fuel rate of $75 \%$, char of $10 \%$, and the rest non-condensable gases were estimated at the end.
\end{abstract}

Conclusions: It can be concluded that the medical plastics can be recycled into oil due to their thermoplastics nature having high oil content and the waste to energy conversion can potentially reduce the volume of PPE plastic wastes.

Keywords: PPE plastics, COVID-19, Characterization, Pyrolysis, Fuel

\section{Highlights}

- Polymer type identification of the medical face mask and glove are carried out.

- PPE wastes generated during pandemic affect waste management.

\footnotetext{
*Correspondence: taaaad82@gmail.com; bassa.ched@gmail.com

${ }^{1}$ Faculty of Chemical and Food Engineering, Bahir Dar Institute of Technology-Bahir Dar University, Bahir Dar, Ethiopia

2 Bahir Dar Energy Center, Bahir Dar Institute of Technology-Bahir Dar

University, Bahir Dar, Ethiopia
}

- The COVID-19 pandemic surges carbon footprint to the environment.

- PPE waste handling methods before reusing were highlighted.

- Fuel recovery through pyrolysis for sustainable waste management was stated.

- The environmental impacts of PPE wastes during the COVID-19 scenario were discussed. 


\section{Introduction}

Global communities are becoming highly dependent on utilizing plastic polymers since commercial production began in about 1950. These days, plastics are become global demand due to simplicity, flexibility, low density, and low production costs. The worldwide plastic production in the globe has been projected at approximately 300 million tons per year and is endlessly increasing every single year (Miandad et al. 2016; Ratnasari et al. 2017). Accordingly, plastic-made material usage and plastic waste production are rising at an alarming rate and its short service life accelerates the plastic waste generation every day (Miandad et al. 2019). Nowadays, the COVID pandemic era has caused an increase in the amount of plastic waste and medical waste, personal protective equipment (PPE), generation worldwide aplastic pollution in the environment (De-la-Torre and Aragaw 2021). Consequently, billion times the tones of extra plastic products have been producing in the globe for the protection of COVID-19 transmission. For instance, human beings are using and disposing of roughly 129 billion face masks and 65 billion plastic gloves every single month globally. According to (Mahbubani 2020) reported in March 2020, 89 million face masks, 76 million hands-on gloves, and 1.6 million protective goggles are required monthly worldwide. So, around 200 Billion facemasks and gloves are going into the environment every month. As a result of a one-time use of these surgical masks followed by their disposal during this COVID-19 augments the burden of polymer on the globe (Jain et al. 2020). Therefore, the use and mismanagement of medical waste by the COVID-19 pandemic is contributing to the increasing plastic contamination. In the meantime, the persistence of PPE deposes of the COVID-19 pandemic will probably be a common plastic debris item that existed in the surroundings for decades. Moreover, single-use disposable plastics have been recognized as a major cause of micro-plastic litter in the environment (Schnurr et al. 2018). Particularly, recent studies validate that the medical face masks are potential sources for micro-plastic pollution in the water systems, and become an environmental threat in the COVID-19 scenario (Aragaw 2020). Thus, the current pandemic caused an increase in the amount of plastic and medical waste generation. Due to this reason, an abundant amount of non-biodegradable polymers including PPE is now disseminated widely around the world in different forms and applications. As a result, an enormous quantity of macro-plastics and their fragmented particles are disposed to the surroundings as well as the risk of the environmental pollution load is predicted as doubling and more than doubling year to year. Undeniably, this PPE plastic management becomes an exceptional concern due to the risk of biohazards nature. Unfortunately, a consistent PPE waste management policy has not been achieved due to the high bio-hazardous potential of the waste (Bdour et al. 2007). In addition, the heterogeneous composition of PPE waste makes it challenging for proper separation and recycling (Wu et al. 2019) (Anuar Sharuddin et al. 2016). Furthermore, recycling only delays final disposal and the plastics obtained have limited economic and technological characteristics. Another option of landfills of plastic offers high resistance to degradation by microorganisms at room temperature and therefore persists for long periods(Jain et al. 2020; Ma et al. 2017). Consequently, conventional landfill practices are losing their acceptance due to harmful environmental effects and the low degradation nature of plastic polymers (You et al. 2020). In these perspectives, thermal destruction treatment offers the utmost reliable disposal route for PPE (Al-Salem et al. 2017) (Qin et al. 2018). Among the thermal degradation processes, incineration of PPE is the usual practice for the disposal of PPE (Geyer et al. 2017), but it lacks the technical merit of air pollution controls (Makarichi et al. 2018). Similar to the public bio-medical wastes, the COVID-waste has been incinerated at a temperature above $1100^{\circ} \mathrm{C}$ (Ilyas et al. 2020). Thus, several toxins are generated in place incineration like furan, and dioxins cause severe health problems (Aragaw 2020) (Ilyas et al. 2020). In addition, incineration along with flue-gas purification also required additional costs and load to the worker. Hence, the operation of an incineration facility with flue-gas cleaning for a small quantity of PPE wastes is not feasible and applicable for handling alternative technologies (Ilyas et al. 2020). Besides, the incineration of chlorine-containing plastics such as PVC generates toxic chemicals that cause cancer, if not done at the right temperature leads to adverse effects on the ecosystem (Klemeš et al. 2020).

Accordingly, finding a reliable disposal platform for PPE beyond incineration and landfilling has great importance (Qin et al. 2018). In the future, pyrolysis offers an effective means for reusing via recovering energy eradicate waste management problems (Burra and Gupta 2018). Because pyrolysis has superior merit towards pollution and a decrease in the carbon footprint of plastic products compared to other thermal treatments(Al-Salem et al. 2017). Moreover, it does not need earlier separation of dissimilar waste plastics; hence a mix of plastics can also be converted into crude bio-oil, which is probably reprocessed for the generation of energy based on end-users and commercial applications. To this end, the present study aims to reduce the use of plastics (SUPs) arising from the surge in disposal PPE usage with a particular focus on pyrolysis as a means of the conversion of PPE (facemask and surgical glove) constituent plastics to 
fuel. The experimental characterization of polymer type and analysis of waste recovery potential via pyrolysis was done on a lab-scale basis including highlighting the handling and pretreatment options of the medical wastes. The key experimental results; polymer type identification, waste conversion rate, and future perspectives were reported for waste management recommendations for future implications.

\section{Materials and methods}

\section{PPE waste handling and preparation for upcycling}

The specific personal protectives components for healthcare workers $(\mathrm{HCW})$ comprise gloves, gowns, shoe covers, head covers, masks, respirators, eye protection, face shields, and goggles. Each personal protective components either alone or in combination have a specific application for contamination prevention. For instance, gloves and grows are worn to protect directly handling potentially infectious materials or contaminated surfaces as part of standard precaution or contact precaution. While shoes and head cover are worn for protection of the likely exposure to a polluted environment as part of full barrier safety measures against airborne organisms, or contact with a contaminated environment is anticipated. Another PPE infectious control equipment is mask and respirators consists of surgical masks, disposable respirator (N95), powered air-purifying respirator (PAPR), and Self-contained breathing apparatus (SCBA) respirators. All these protective types of equipment are worn for protection of mouth and nose from splattered body fluids, microorganisms (bacteria and viruses), and respirators filter the air before inhaling it. Furthermore, goggle and face shield personal protectives provides protection of eyes from splatters and splatter protection to facial skin, eyes, nose, and mouth respectively as a standard precaution for medical applications(Minnesota Department of Health 2020).

All the stated personal protectives are disposable medical wastes that have high risks of infections with pathogens, viruses, and bacteria. Principally, all COVIDwaste is recognized as hazardous biomedical wastes and required disinfection before use (Ilyas et al. 2020). As a result, the effective management and safe handling practices of this waste are paramount. Ilyas et al. proposed the COVID-19 hospital and biomedical wastes treatment technique (incineration, thermal, and chemical treatment) for disinfection and reprocessing of medical wastes (Ilyas et al. 2020). Among the decontamination method of PPE, incineration, and alternative thermal disinfection are intended for waste volume reduction rather than reprocessing to different products (Ilyas et al. 2020). Despite the rigorousness of sterilization modalities, conventional sterilization technologies also degraded the quality of PPE. Thus, the one-time-use medical plastics are not suitable for re-using later the post-treatment. In addition, high-level disinfection is found to change characteristic personal protective components (Rowan and Laffey 2020a). Hence, the above-described handling technologies are suitable for the disinfection of contaminates for safe disposal only. However, the chemical (chlorine and non-chlorine), vaporized hydrogen peroxide $\left(\mathrm{vH}_{2} \mathrm{O}_{2}\right)$, and UV-radiation (typically, Claranor, France, and (Nanoclave cabinet, Ireland) effectively disinfects the virus spores without reducing the volume of disposable medical waste (Rowan and Laffey 2020b) (Barcelo 2020). Therefore, these treatment methods provide an opportunity for re-use with no threat to change in intrinsic characteristics and quantity of plastic waste volume. With this regard, chemical, $\mathrm{vH}_{2} \mathrm{O}_{2}$, and/or UV radiation treatment technology could be deployed for proper handling for later reusing of disposable plastic wastes. But in the present study, single-use face masks and gloves were purchased from a pharmacy store in Bahir Dar-Ethiopia for lab-scale analysis. Then samples were chopped into small pieces. However, in the real case, medical wastes pretreatment should be implemented before reprocessing to other products using proper disinfection techniques for specific repurposing of it.

\section{Characterization of medical waste plastics}

PPE recovering must consider material composition, the functionality of post-treatment, along with appropriate fit for purpose. Otherwise, it is important to follow the PPE manufacturer governing guidance of the detailed features of the PPE. However, PPE is thermally sensitive while it may not found within the manufacturer's design quality proposed for reprocessing (Rowan and Laffey 2020b). So, before upcycling of the disposable PPE, its polymer type identification, thermal degradation property should be identified using Fourier-transform infrared spectroscopy (FTIR) and Thermo-gravimetric analysis.

\section{FTIR analysis}

The chemical structure determination is an important technique that can give us the basic information to identify the polymeric type. The face mask and glove were chopped separately with the scissor and grounded with mortar and pestle. The pellets were prepared with reagent grade potassium bromide $(\mathrm{KBr})$ powder with mechanical pressing. The spectral analysis was analyzed using a JASCO-6600 spectrometer with a scanning range of $400-4000 \mathrm{~cm}^{-1}$. 


\section{Thermo-gravimetric analysis}

The thermogravimetry (TGA) instrument, BJ HENVEN (ATAT 2012) was used for the differential thermo-gravimetric curve determination of medical face masks and glove plastic polymers. Firstly, the medical face mask and gloves were chopped with a small size to be appropriate for the instrument crucible. The $6.5 \mathrm{mg}$ mass chopped medical face mask and glove were separately weighed with analytical balance (KE-ABJ80-4NM), and are put on the ceramic crucible. As a blank, the empty crucible was used aside from the sample crucible. The differential thermalgravimetric analysis (DTA) was heated from ambient temperature to $600^{\circ} \mathrm{C}$ with a heating rate of $15^{\circ} \mathrm{C} / \mathrm{min}$, a TGA range of 100 , and a sampling cycle of 1500 . The time for complete thermal analysis was required $40 \mathrm{~min}$.

\section{Pyrolysis and experimental setup}

The pyrolysis experimental setup is shown in Fig. 1. It comprises an insulated $10 \mathrm{~cm}$ in diameter and $13.5 \mathrm{~cm}$ height steel closed can reactor, a $10 \mathrm{~mm}$ flexible connection pipe, and a water-jacketed receiving flask. The reactor vessel and a cold trap are connected with a flexible metallic hose. Before the experiment, raw materials (fresh face masks and surgical gloves) are purchased from local pharmacies and chopped into pieces. Then, $300 \mathrm{gm}$ of face mask and surgical glove each weighing $150 \mathrm{gm}$ was feed to the reactor. The reactor contents are then sealed and placed in the heating mantle. The thermal treatment was performed at $400^{\circ} \mathrm{C}$ for $1 \mathrm{~h}$ in the closed air system with no vacuum process applied during this thermal cracking process. Finally, the pyrolysis product was sent to the water jacket cold trap and allowed to cool to room temperature.

Hypothetically, waste plastic pyrolysis was taken place at $350-500^{\circ} \mathrm{C}$ for two h. Upon heating, the plastics are

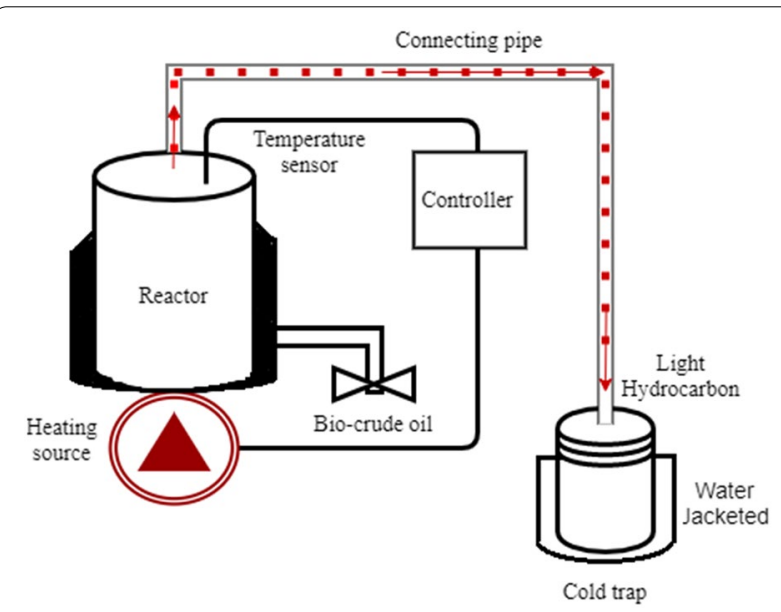

Fig. 1 A benchtop pyrolysis setup for fuel production subjected to depolymerization, pyrolysis, thermal cracking to obtain pyrolyzed fuel oil. Heat is applied from $100^{\circ} \mathrm{C}$ at the start to initiate melting the plastics, the melted waste plastic turn into liquid slurry form when the temperature is increased gradually. When the temperature is raised to $270^{\circ} \mathrm{C}$ liquid slurry turns into vapor for the first $25 \mathrm{~min}$ and the vapor is then passed through a connection tube to the condenser unit. Thermal cracking continues for the next $35 \mathrm{~min}$, while the temperature was kept at $400^{\circ} \mathrm{C}$. During this thermal cracking process, some light gases are produced and the condensable pyrolyzed gases were continuously swept out from the reactor. In the end, the entire heated vapors coming out of the reactor are condensed on a cool water-jacketed receiver for cooling of the vapor. The gaseous hydrocarbons at a temperature of about $400^{\circ} \mathrm{C}$ are condensed to about room temperature $30-35^{\circ} \mathrm{C}$ by direct contact to a water-jacketed cold trap. However, heating was limited for up to $1 \mathrm{~h}$ time, because of difficulty in maintaining a gas seal resulting in gas leakage in this small-scale experimental setup. At the end of the experiment, the reactor and cold trap content are weighed and measured for pyrolysate components analysis of recovered crude liquid oil and remaining char from the specified sample of disposable face mask and gloves.

In large scale applications, PPE used for healthcare from health and quarantine centers will be collected along with rigorous infection control practices and decontamination methods. After precaution handling, the SUP waste then goes to the central thermal treatment plant for resource recovery. Thus, the wastes can be converted to value-added fuels similar to other solid waste and plastic pyrolysis. Moreover, evidence has shown that a substantial increase in the use/consumption of SUPs and PPE, along with the increment in medical waste inherent to the pandemic, is likely leading to an excess single-use plastic waste generation that potentially used for advanced resource recovery (Prata et al. 2020). The large-scale conversion of PPE and SUP in a central pyrolysis plant will alleviate a sudden surge in demand for consumption of plastic products by the general public, healthcare workers, and service workers imposed by the pandemic and the plastic waste trade stress. Consequently, recovered resources from PPE and SUPs introduced the public impression of medical plastic waste from pain to advance through precise matching the socioeconomic, energy, and environmental demands.

\section{Results and discussion}

FTIR and polymer type identification

Fourier-transform infrared spectroscopy (FTIR) spectral analysis of medical face mask and glove were shown in Fig. 2. The peak at $611 \mathrm{~cm}^{-1}$ for the surgical face mask 


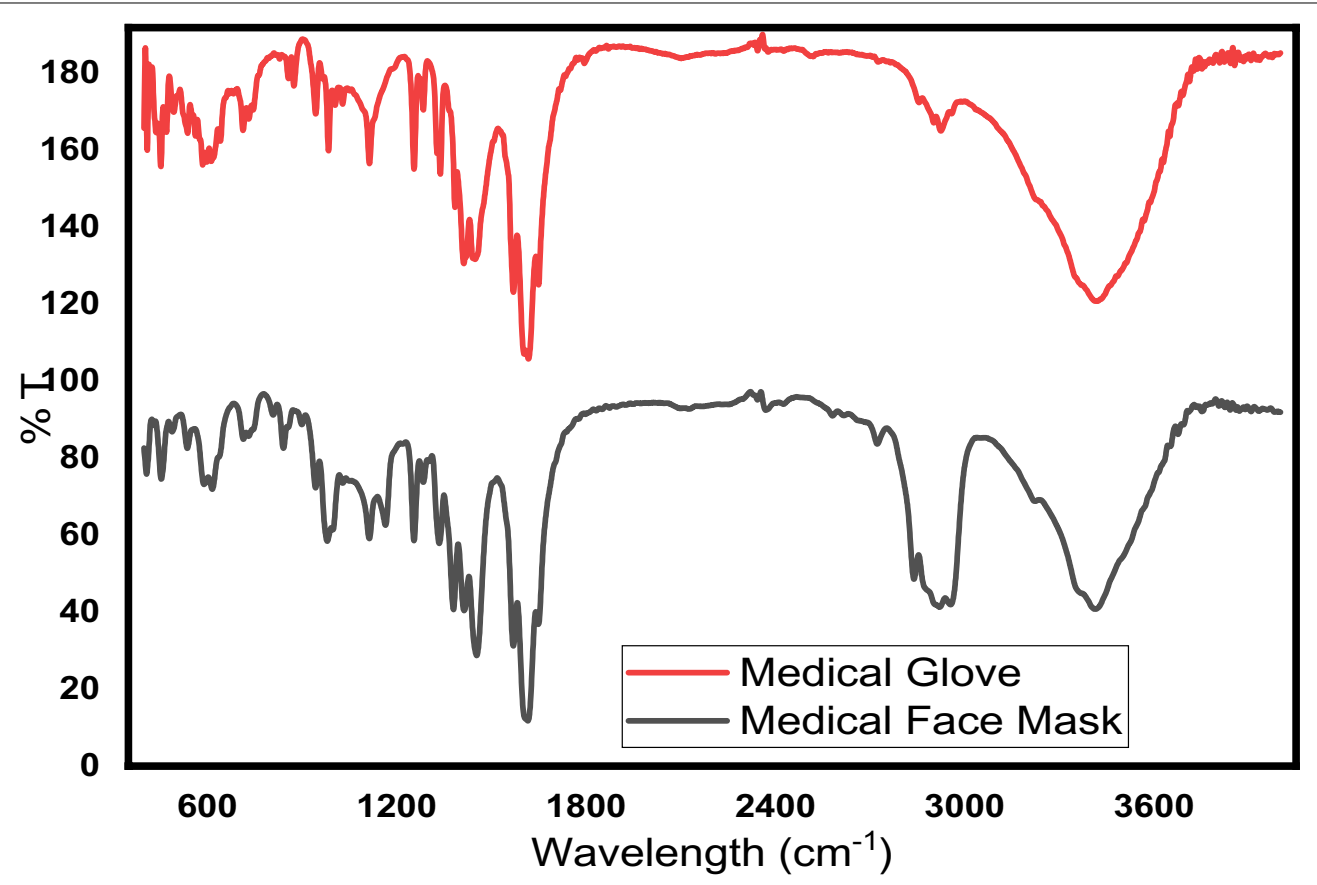

Fig. 2 Infrared Fourier transform spectrum absorption bands of medical face mask and glove

is corresponding the $=\mathrm{C}-\mathrm{CH}_{3}$ in aliphatic and phenyl in romantic vibration the monomeric polypropylene polymer (Zhang et al. 2013). The sharp and clear peak at $2900 \mathrm{~cm}^{-1}$ for both medical face mask and glove attributes for the $\mathrm{C}-\mathrm{H}$ vibration (Nam et al. 2016). The peaks around $1113 \mathrm{~cm}^{-1}$ are assignments for the $\mathrm{C}-\mathrm{O}$ stretc. hing in the polypropylene constitute of face mask and nitrile rubber made up of medical gloves. The peaks at 1454 and $1380 \mathrm{~cm}^{-1}$ for both face mask and glove are the assignments of the symmetry deformation of $-\mathrm{CH}_{2}-$ on the aliphatic hydrocarbons (Zhang et al. 2013). Diao et al. reported that the non-woven, and pure polypropylene fabrics of IR spectral were similar to the present study (Diao et al. 2017). The sharp and low band peaks at 1619 and $1545 \mathrm{~cm}^{-1}$ for both glove and face mask is assigned for the carbonyl $(\mathrm{C}=\mathrm{O})$ stretc.hing vibration of the primary amide for the polypropylene face mask and the nitriles functional group $(-\mathrm{C} \equiv \mathrm{N})$ stretc.hing for nitrile rubber gloves, respectively (Chen and Sun 2005). The broadband and clear peaks for the two polymers, PVC and polypropylene, around $3414 \mathrm{~cm}^{-1}$ attributes the aliphatic or aromatic O-H stretc.hing. The presence of the nitrile group in the rubber type of polymer in the glove plastic was identified can be confirmed at the peak of $2340 \mathrm{~cm}^{-1}$, and the peak at $597 \mathrm{~cm}^{-1}$ is a representative of C-Cl stretc.hing vibrations (Nirmal Ghosh et al. 2017). In general, spectral vibration and stretc.hing can provide evidence face masks and gloves are made up of PVC and polypropylenes which are thermoplastic types of polymer that suggest that it can be used for fuel energy through the pyrolysis process.

\section{Thermogravimetric analysis and thermal properties}

The derivatives of the thermogravimetric curve for the medical face mask and hands-on gloves as a function of temperature were computed as shown in Fig. 3, which is commonly used to represent the weight loss of TGA thermograms. The differential thermogravimetric (DTA) curve patterns can give the quantified records on the maximum temperature of the exothermic and endothermic signals. Besides, the DTA pattern, quantified the part of the exothermic and endodermic part yielded the enthalpies associated with the thermal phenomena of the materials. A small endothermic around $210{ }^{\circ} \mathrm{C}$ of the medical glove is the melting point stage of the PVC polymers which officially know that in the range of 100 to $260{ }^{\circ} \mathrm{C}$ depending on the manufacturer additives (Causin et al. 2009). The endothermic peak around $431{ }^{\circ} \mathrm{C}$ for glove plastic polymer is observed. This peak is due to the decompositions of poly-cis-1,4-isoprene organics which contained doing the formulations of PVC glove (de Oliveira et al. 2006). The derivative of the curve concerning temperature originated by the thermo-oxidative degradation and informative with the corresponding thermogravimetric mass loss. An exothermic peak at 475 and $495{ }^{\circ} \mathrm{C}$ and an endothermic peak at $485{ }^{\circ} \mathrm{C}$ for 


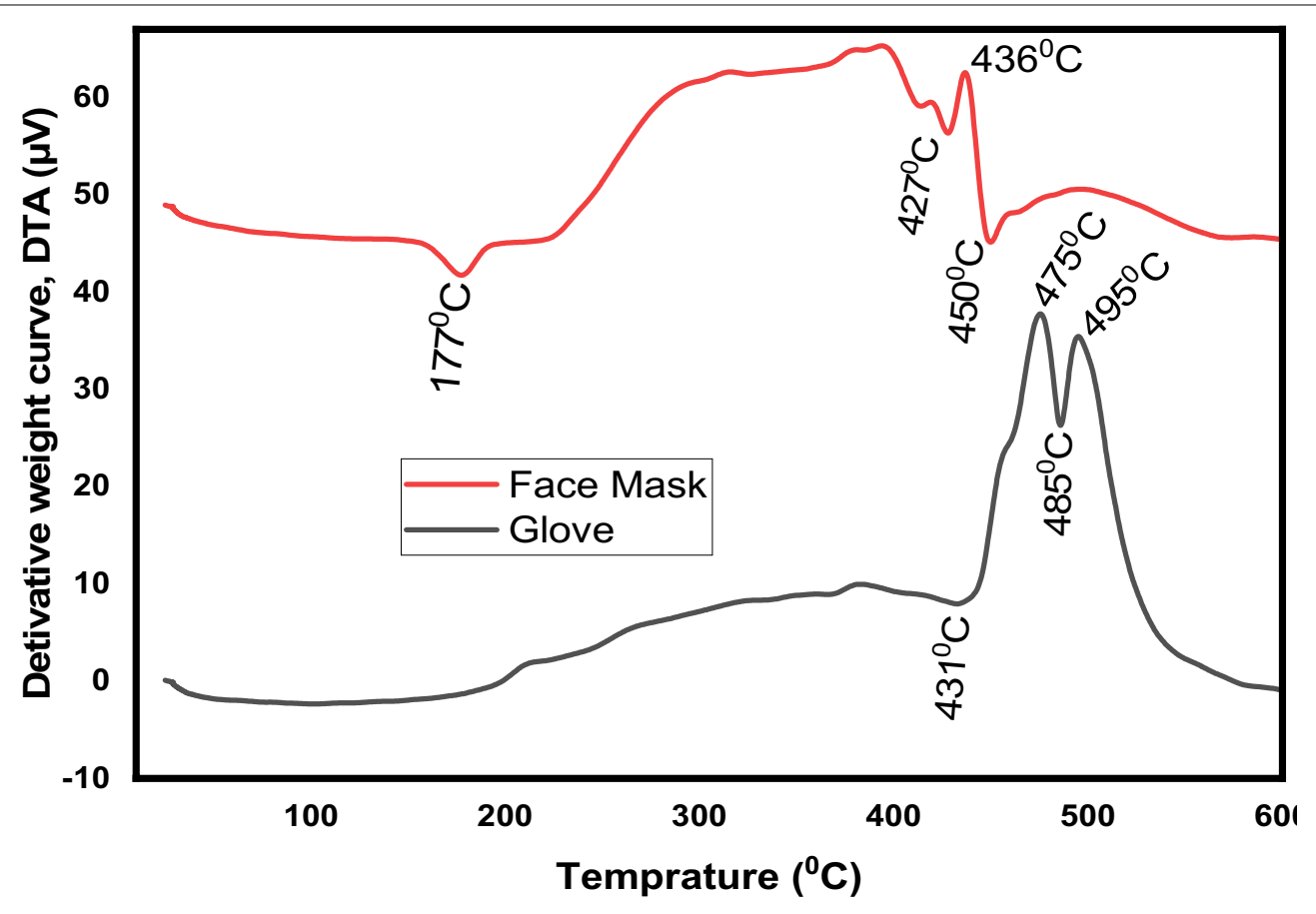

Fig. 3 differential thermogravimetric curves of medical face mask and hand-on gloves
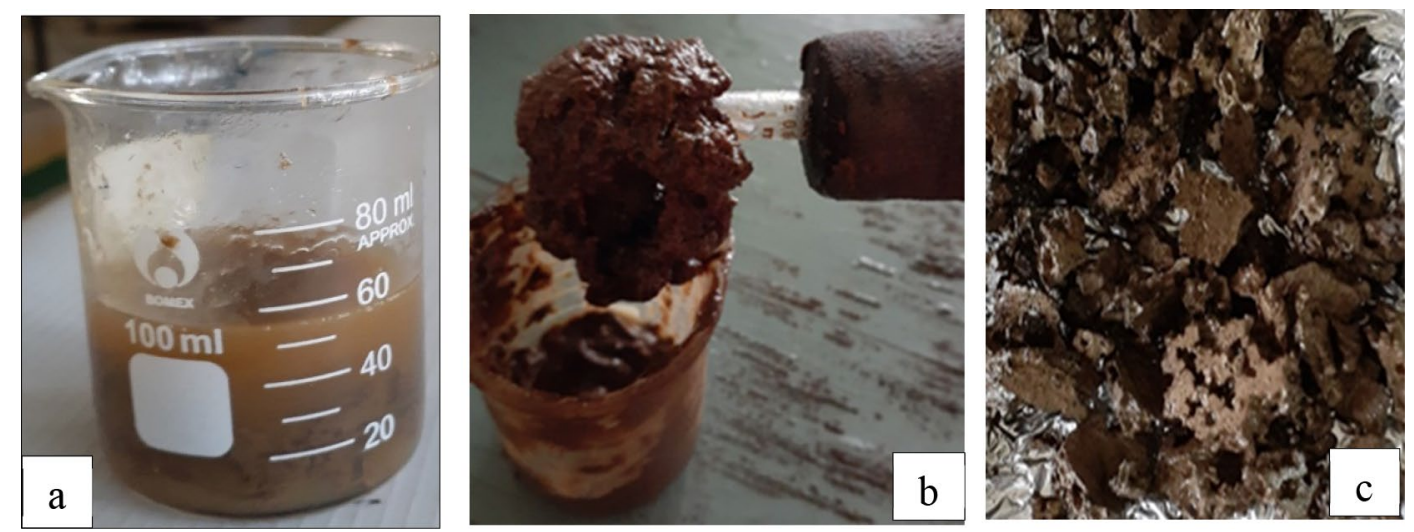

Fig. 4 Pyrolysis products (a), b Bio-crude oil, c Char

the glove ascribed to the combustion of the main polyisoprene chains and the organic additives (Agarwal et al. 2011). The endothermic peak at $175{ }^{\circ} \mathrm{C}$ of the medical hand-on glove is the melting point of the polypropylene plastic polymers. The optimized melting point of the polypropylene is ranged from 160 to $166^{\circ} \mathrm{C}$ depending on the atactic materials and crystalline (Rychlý et al. 2011).

Additional peaks in the derivative curve from 300 to $450^{\circ} \mathrm{C}$ for a medical face mask are due to the deformational or melt agglomerate transition phase formed in the polypropylene plastic polymers (Majewsky et al. 2016). In this study, the medical face masks are identified as a polypropylene type of plastic polymer, and the medical handon gloves are identified as nitrile rubber types of plastic polymers. Thus, it can be concluded that the identified medical plastics can be recycled into fuel energy due to they are thermoplastic polymers having high oil content.

\section{Pyrolysis products}

The primary products from a mixed face mask and surgical gloves pyrolysis was liquid pyrolysis oil and solid char shown in Fig. 4. 
As seen in Fig. 4a, tar (liquid oil and wax) and char were obtained at a temperature of $400^{\circ} \mathrm{C}$ for $1 \mathrm{~h}$ of operation. The jelly-like liquid in Fig. $4 \mathrm{~b}$ is produced from the heavy aromatic compound found in gloves. From total feed samples weight, 225 grams of crude oil and $30 \mathrm{gm}$ of plastic residue (char) were obtained at the end of the experiment. Conferring to the experiment outcome, the recovery rate is estimated as 75 wt.\%, liquid, $10 \mathrm{wt} . \%$ char, and the rest were released as non-condensable gases other than bio-crude oil. The present study product yields are in line with literature report the of pyrolysis of plastic wastes where $75-80 \%$ liquid oil and waxes have been produced at temperatures ranges of $500-650{ }^{\circ} \mathrm{C}$ (Mastral et al. 2002; Fakhrhoseini and Dastanian 2013). Furthermore, the yield was also in the range of thermal pyrolysis process common municipal plastic waste. According to the review reports by (Abnisa and Daud 2014), up to $80 \%$ of liquid oil can be obtained through pyrolysis of plastic waste around $500{ }^{\circ} \mathrm{C}$. Similarly (Ahmad et al. 2014) achieved $98.7 \% \mathrm{w} / \mathrm{w}$ liquid, $69.8 \% \mathrm{w} / \mathrm{w}$ gas, $28.8 \% \mathrm{w} / \mathrm{w}$, and residue $1.34 \% \mathrm{w} / \mathrm{w}$ from pyrolysis of polypropylene at $400{ }^{\circ} \mathrm{C}$. (Sakata et al. 1999) also, investigate the pyrolysis of $\mathrm{PP}$ at a temperature of $380^{\circ} \mathrm{C}$ and found 80.1 $\mathrm{w} / \mathrm{w} \%$ liquid yields, $6.6 \mathrm{wt} \% \mathrm{t}$ gas yield, and $13.3 \mathrm{wt} . \%$ solid residues. FakhrHoseini and Dastanian 2013 reported $82.12 \mathrm{wt} \%$ liquid was found from pyrolysis of PP at $500^{\circ} \mathrm{C}$. (Demirbas 2004) also revealed that pyrolysis of PP yields $48.8 \mathrm{wt} \%$ liquid, $49.6 \mathrm{wt} \%$ gas, and $1.6 \mathrm{wt} \%$ char at a high temperature of $740^{\circ} \mathrm{C}$. In addition, plastics are essentially polymers with major constituting of carbon and hydrogen atoms (Al-Salem et al. 2017). Particularly, PE and PP have carbon content ranging from 85.5-86.1\% (Sørum et al. 2005; Encinar and González 2008). Such a high carbon content present in a facemask (PP) makes pyrolysis a favorable treatment to re-use for fuel. Whereas handon gloves (PVC) have high aromatic content (Al-Salem et al. 2017). Hence, PVC plastics pyrolysis yields high portions of aromatics. With this regard, the fuel recovery from the PPE wastes is reasonable for reuse and in good agreement with the previous studies. However, the yield and the product composition of pyrolyzed plastic depend upon the residence time and waste polymer type of plastic waste (Miskolczi et al. 2004). Indeed, the crude oil has a similar calorific value as diesel or gasoline up on up upgrading through fractionation state (Erdogan 2020).

\section{Potential applications of pyrolysis products and implication for energy options}

A plastic waste recovery against pollution during the pandemic for sustainable measures desires the plastictype waste specification for action and plans (You et al.
2020). As confirmed by the FTIR, both face mask and surgical gloves are polypropylene and Nitrite rubber (PVC) thermoplastic polymers. This kind of polymer can be converted efficiently to value-added biofuels through thermal treatment (Jain et al. 2020). But, the researchers argued that PPE conversion into biofuels is not an effective environmental solution to manage plastic waste generated by the pandemic (Patrício Silva et al. 2020). Rather scaling up in innovation for sustainable and green plastics solutions, and developing dynamic and responsive plastic waste management systems should be an immediate action during and post-pandemic. Consequently, the need of rethinking and redesigning plastics (i.e., development of eco-friendly and bio-based solutions at an affordable price), along with the improvement of recycling streams to ensure proper end-of-life for those products during pandemic scenarios, should be at the highest priority. Reusable alternatives (such as for PPE) should be produced and financially incentivized at the industrial sector level (Patrício Silva et al. 2020). In addition, infectious disease institutes reported that coronaviruses can stay on commonly recycled materials for up to a few days, particularly lasts longer on plastic than other recycling materials during the pandemic aggravates the risk of contamination (Kaufman and Chasan 2020). However, the team of Indian scientists who conducted the study has found that a simple chemical process is sufficient to convert the plastic material present in PPE kits into biofuel and reported as it can also offer a long-term energy source(Jain et al. 2020); (Energy World 2020). Recently, another alternative waste to energy sustainable options has been reported by a group of scientists from the Swansea University with the led of Dr Moritz Kuehnel. The investigation is about hydrogen fuel production from PPE via photoreforming using sunlight, and they said it is cost-effective and affordable for developing countries, even. It involves the breakdown of PPE into hydrogen using a photocatalyst by absorbing light and converting it into energy to promote chemical reactions. This leads to the breakdown of plastic waste and the conversion of water into hydrogen (Steffan 2020).

Furthermore, evidence has shown that recycling of waste plastic and their mixtures have been used for the fuel production process at the medium heat temperature range from 200 to $420{ }^{\circ} \mathrm{C}$ (Sarker et al. 2012). Moreover, it is evident from the studies of Miandial et al. that the liquid oil synthesized from the catalytic thermal treatment of plastic polymers ( PS, PE, PP, and PET) in particular or a mixture of the different proportion has a high quantity of range of aromatic compounds that are found in petroleum fuel products (Miandad et al. 2019). The 
liquid oil from the pyrolysis of these plastic wastes has a high heating value (HHV) of 41.7-44.2 MJ $/ \mathrm{kg}$, near to the conventional diesel (Miandad et al. 2019). Accordingly, the pyrolysis oil obtained from several plastic wastes has the prospective to be recycled as a substitute for conventional energy sources. According to (Lee et al. 2015) and (Rehan et al. 2016), electricity generation from pyrolysis liquid oil is attained in a diesel engine. (Saptoadi and Pratama 2015) effectively utilized Pyrolytic liquid oil as a substitute in a kerosene stove. Besides, the aromatic compounds can be used as a resource for polymerization in many chemical industries (Sarker et al. 2012; Shah and Jan 2015). In addition, several scholars used the produced liquid oil in transport sectors as fuel after mixing with commercial diesel at different ratios. Several investigations were also performed to discover the potential of pyrolysis liquid oil from the perspective of locomotive performance and automobile exhaust gas emission. (Nileshkumar et al. 2015) and (Lee et al. 2015) stated that a 20:80\% mixing ratio of pyrolytic oil and conventional diesel, respectively, offered analogous engine performance effects than conventional diesel.

The remaining char could be easily utilized as a fuel or a raw material for other petrochemicals (Kabakcı and Hacıbektaşoğlu 2017). The pyrolysis solid residue is composed of condensed organic residues and the inorganic phases, with an average high heating value of $28.5-29 \mathrm{MJ} /$ kg (Kabakcı and Hacıbektaşoğlu 2017). The char can also be activated via steam and thermal activation for methylene blue dye adsorption from wastewater (López et al. 2011) (Bernardo 2011). Similarly, the char is also used for the synthesis of a novel carbon-metal adsorbent for Congo red in wastewater. Furthermore, the char can be used as a feedstock for the synthesis of activated carbon (Bernardo 2011) (Miandad et al. 2016).

The toxic by-products during pyrolysis can be controllable by adopting catalysts during the process and altering the operational parameters (heating rate, temperature, duration, etc.). Pyrolysis of plastic in a thermal closed reactor under an inert environment and/or $\mathrm{CO}_{2}$ also prevents toxic by-products formed through carbon rearrangement (Jung et al. 2021). Particularly, carbonaceous materials made for PPE can turn into three phases of pyrogenic products, including syngas $\left(\mathrm{H}_{2}, \mathrm{CH}_{4}\right.$, and $\mathrm{CO})$, condensable gaseous/liquid hydrocarbons, and solid residue (char) in single or multi-stage pyrolysis over catalyst. Moreover, toxic by-products could be minimized in the thermal degradation of plastic in presence of a catalyst. This process improves the production of a large quantity of liquid oil and condensable hydrocarbon due to its capability for dehydrogenation potentially reduced toxic by-product with technical completeness in terms of air pollution controls.

\section{Impacts of Covid-19 plastics on the environment}

Following the increase of plastics waste and alterations in waste management plans, many reports tried to estimate their environmental footprint considering different scenarios. For example, the (Hub 2020) studied a life cycle assessment on UK-wide adopted faces. The study showed that the use of reusable masks considerably lessens the extent of waste by $95 \%$, followed by reusable face cover with one-use filters $(60 \%)$. Reusable face with no filters that were washed by machine had the overall least impact on climate change $\left(<2.00 \mathrm{E}+008 \mathrm{Kg} \mathrm{CO}_{2}\right.$-eq).

On the Other hand, single-use face shield and reusable face shield with one-use filters had the highest role to climate change $(\sim 1.47 \mathrm{E}+009$ and $1.50 \mathrm{E}+009$; respectively $\mathrm{Kg}$ $\mathrm{CO}_{2}$-eq.). Therefore, the deployments of disposable masks worsen climate change by 10 folds than reusable masks.

Though there is no current valuation for gloves, the previous investigation has shown the use and mass-scale production of the glove may be a threat to the environment. For instance, synthetic rubber gloves manufactured in Malaysia utilized $10.0413 \mathrm{MJ}$ of energy per production per $\mathrm{kg}$ with impacts extremely reliant on energy production (Hub 2020). Meanwhile, in Thailand, the overall carbon footprint release is estimated to around $42 \mathrm{~kg} \mathrm{CO}_{2}$-eq per 200 pieces of rubber glove (Usubharatana and Phungrassami 2018). Considering the expected suggested regular monthly use of 65 billion gloves globally (Prata et al. 2020), and the earlier projected carbon footprint release by (Usubharatana and Phungrassami 2018), results in the release of $1.44 \times 10 \mathrm{E}+010 \mathrm{Kg}$ $\mathrm{CO}_{2}$-Eq. kg (14 Mt $\mathrm{CO}_{2}$-eq.). The deployment and choice of SUP, principally plastic bags have been in doubt over the paper and cotton in the COVID-19 period. With this scenario, the reusable options of PPE kits are the foremost step to decrease the global warming potential that comes from the use of single-use plastic and PPE (Hub 2020). Furthermore, incineration and landfilling disposal of COVID-19 pandemic plastic waste worsen the air quality in moderateto continuing periods (Prata et al. 2020). Generation $\mathrm{CO}_{2}$ and $\mathrm{CH}_{4}$ are released in significant amounts during plastic waste decomposition in landfills or during the burning of plastics waste (Prata et al. 2020). For instance, in the UK, incineration results in 0.179 tons of $\mathrm{CO}_{2}$ eq carbon footprint per ton of MSW while that landfilling results in 0.395 tons of $\mathrm{CO}_{2}$ Eq. per ton of MSW (Jeswani et al. 2013).

\section{Conclusion, Perspectives, and Recommendations for Future work}

The rapid increase in plastic production and new plastic wastes addition due to pandemics to the environment aggravates the ecosystem threat for the forthcoming years. Particularly, the word plastic now appears to be denoted by the phrase "enemy of the environment". But, plastic in itself is not an enemy when used and disposed 
of properly. The plastic waste problem is neither inherent to its natural surroundings nor a problem in itself. The concern of plastic waste is our approach towards it. Meaning, it is part of the production process of various products required for social progress and welfare. The challenge is what we do with such plastic wastes. However, currently, there is huge production and utilization of PPE kits to save life lead to medical waste disposal a big concern. Particularly, the demand for the face shield and gloves are not declined as expected in the post-pandemic period up to 2025. Besides, the world is in economic crisis and ecological imbalance enforced by pandemic aiming to fight COVID-19. Thus, to eradicate the environmental threat of plastic waste particularly disposable medical waste, formulating recycling, and /or reusing alternative options as sustainable management is required attention. Some of the solutions could be to redesign the biodegradable and reusable PPE. For instance, the Vietnamese Company, shoes, and Canada's University of British Columbia BioProducts Institute produced a biodegradable face mask. While the Edinburgh study suggests cloth masks to reduce disposable PPE. Beyond the use of biodegradable and reusable PPE, recycling plastic wastes should be sought attention to preserve the sustainability of the management strategy. Owing to the thermoplastic nature of PPE kits, the authors proposed thermal degradation as an effective means of recycling. The pyrolysis experimental investigation of PPE plastics wastes converted more than $75 \%$ of waste to bio-crude oil (tar). Thus, the suggested method of recycling PPE via pyrolysis is an indicative measure to alleviate the disposal problem of the single-use medical wastes. Therefore, the reprocessing of PPE to value-added products along with proper handling eases disposal problems and provides energy sources at the same time. Thus, the contests of PPE waste and the estimated rise in energy demand could be tackled by the production of petroleum fuel from such PPE kits. Even though these medical waste disposals will be significantly reduced during the post-pandemic, the proposed strategy could be applied similarly to other plastics that existed in solid waste streams. It has been noted that the quality and yield of pyrolysis products are highly dependent on temperature and the presence of a catalyst. So the work needs further investigation using a variety of catalysts over a range of temperatures $(300-$ $500^{\circ} \mathrm{C}$ ) to enhance the pyrolysis process and efficiency. In addition, crude oil obtained also needs further upgrading and GC-MS accurate quantitative analysis of chemical components of oil would be required. On top of that, a detailed technical, economic and environmental impact assessment of on potentials and challenges of pyrolysis of PPE waste to fuel using life-cycle assessment (LCA) should be conducted for strategies and policymakers.

\section{Abbreviations}

TGA: Thermogravimetric analysis; DTA: Differential thermogravimetric analysis; FTIR: Fourier transform infrared spectroscopy; PVC: Polyvinyl chloride; PPE:

Personal protective equipment; SUPS: Single-use plastics.

\section{Acknowledgements}

-We would like to thank those organizations and scholars whom we have used previously findings related to this work and laboratory resources including the present authors' affiliated institute. The authors also apologize to all intellectuals, and organizations whose involvement in the field of recycling/ reuse methods of plastic wastes and microplastic pollution may have been reviewed by the mistake or inadequately recognized.

\section{Declaration}

The investigation, Final reviewing, and editing.

\section{Authors' contributions}

Both authors have been involved in the characterization and pyrolysis experimental, Conceptualization, Manuscript write up (first and final draft), Visualization,

\section{Funding}

The article was fully self-funded and there is no fund provider for this work.

\section{Availability of data and materials}

All data generated or analyzed during this study are included in the body of the manuscript.

\section{Ethics approval and consent to participate}

This part is not applicable for this article.

\section{Consent for publication}

This part is not applicable to this article.

\section{Competing interests}

We authors have read and understood the policy of the competing interests and declare that there are no competing interests among the authors and they have no known competing financial interests or personal relationships that could have appeared to influence the work reported in this paper.

Received: 29 October 2020 Accepted: 30 December 2020

Published online: 20 January 2021

\section{References}

Abnisa F, Daud WM (2014) A review on co-pyrolysis of biomass: an optional technique to obtain a high-grade pyrolysis oil. Energy Convers Manag 87:71-85. https://doi.org/10.1016/j.enconman.2014.07.007

Agarwal K, Prasad M, Chakraborty A et al (2011) Studies on phase morphology and thermo-physical properties of nitrile rubber blends. J Therm Anal Calorim 104:1125-1133. https://doi.org/10.1007/s1097 3-010-1193-y

Ahmad I, Khan MI, Khan H, Ishaq M et al (2014) Pyrolysis study of polypropylene and polyethylene into premium oil products. Int J green energy 12:663-671. https://doi.org/10.1080/15435075.2014.880146

Al-Salem SM, Antelava A, Constantinou A et al (2017) A review on thermal and catalytic pyrolysis of plastic solid waste (PSW). J Environ Manage 197:177-198. https://doi.org/10.1016/j.jenvman.2017.03.084

Anuar Sharuddin SD, Abnisa F, Wan Daud WMA, Aroua MK (2016) A review on pyrolysis of plastic wastes. Energy Convers Manag 115:308-326. https://doi.org/10.1016/j.enconman.2016.02.037

Aragaw TA (2020) Surgical face masks as a potential source for microplastic pollution in the COVID-19 scenario. Mar Pollut Bull 159:111517. https:// doi.org/10.1016/j.marpolbul.2020.111517

Barcelo D (2020) An environmental and health perspective for COVID-19 outbreak: Meteorology and air quality influence, sewage epidemiology indicator, hospitals disinfection, drug therapies and recommendations. J Environ Chem Eng 8:104006. https://doi.org/10.1016/j. jece.2020.104006 
Bdour A, Altrabsheh B, Hadadin N, Al-Shareif M (2007) Assessment of medical wastes management practice: A case study of the northern part of Jordan. Waste Manag 27:746-759. https://doi.org/10.1016/j.wasma n.2006.03.004

Bernardo MMS (2011) Physico-chemical characterization of chars produced in the co-pyrolysis of wastes and possible routes of valorisation. Bioresour Technol 4:89

Burra KG, Gupta AK (2018) Kinetics of synergistic effects in co-pyrolysis of biomass with plastic wastes. Appl Energy 220:408-418. https://doi. org/10.1016/j.apenergy.2018.03.117

Causin V, Marega C, Marigo A et al (2009) A method based on thermogravimetry/differential scanning calorimetry for the forensic differentiation of latex gloves. Forensic Sci Int 188:57-63. https://doi.org/10.1016/j.forsc iint.2009.03.014

Chen Z, Sun Y (2005) Antimicrobial polymers containing melamine derivatives. II. biocidal polymers derived from 2-Vinyl-4,6-diamino-1,3,5-triazine. J Polym Sci Part A Polym Chem 43:4089-4098. https://doi.org/10.1002/ pola.20906

De-la-Torre GE, Aragaw TA (2021) What we need to know about PPE associated with the COVID-19 pandemic in the marine environment. Mar Pollut Bull 163:111879. https://doi.org/10.1016/j.marpolbul.2020.111879

de Oliveira LCS, de Arruda EJ, Favaro SP et al (2006) Evaluation of thermal behavior of latex membranes from genetically improved rubber tree (Hevea brasiliensis). Thermochim Acta 445:27-31. https://doi. org/10.1016/j.tca.2006.03.027

Demirbas A (2004) Pyrolysis of municipal plastic wastes for recovery of gasoline-range hydrocarbons. J Anal Appl Pyrolysis 72:97-102. https:// doi.org/10.1016/j.jaap.2004.03.001

Diao Z, Wang L, Yu P et al (2017) Super-stable non-woven fabric-based membrane as a high-efficiency oil/water separator in full pH range. RSC Adv 7:19764-19770. https://doi.org/10.1039/C7RA01603D

Encinar JM, González JF (2008) Pyrolysis of synthetic polymers and plastic wastes Kinetic study. Fuel Process Technol 89:678-686. https://doi. org/10.1016/j.fuproc.2007.12.011

Energy World FTET (2020) How Covid-19 PPE can turn into biofuel. In: Energy World.Com. https://energy.economictimes.indiatimes.com/news/oil-andgas/indian-researchers-show-how-covid-19-ppe-can-turn-into-biofuel

Erdogan S (2020) Recycling of Waste Plastics into Pyrolytic Fuels and Their Use in IC Engines. In Sustainable Mobility. IntechOpen

Fakhrhoseini SM, Dastanian M (2013) Predicting pyrolysis products of PE, PP, and PET using NRTL activity coefficient model. J Chem 2013:7-9. https:// doi.org/10.1155/2013/487676

FakhrHoseini SM, Dastanian M (2013) Predicting Pyrolysis Products of PE, PP, and Using PET NRTL Activity Coefficient Model. J Chem

Geyer R, Jambeck JR, Law KL (2017) Production, use, and fate of all plastics ever made. Sci Adv 3:e1700782

Hub HUPWI (2020) The environmental dangers of employing single-use face masks as part of a COVID-19 exit strategy. https://d2zly2hmrfvxc0.cloud front.net/Covid19-Masks-Plastic-Waste-Policy-Briefing.final.pdf. Accessed 22 July 2020.

Ilyas S, Srivastava RR, Kim H (2020) Disinfection technology and strategies for COVID-19 hospital and bio-medical waste management. Sci Total Environ 749:141652. https://doi.org/10.1016/j.scitotenv.2020.141652

Jain S, Yadav Lamba B, Kumar S, Singh D (2020) Strategy for repurposing of disposed PPE kits by production of biofuel: Pressing priority amidst COVID-19 pandemic. Biofuels 1:1-5. https://doi.org/10.1080/17597 269.2020.1797350

Jeswani HK, Smith RW, Azapagic A (2013) Energy from waste: Carbon footprint of incineration and landfill biogas in the UK. Int J Life Cycle Assess 18:218-229. https://doi.org/10.1007/s11367-012-0441-8

Jung S, Lee S, Dou X, Kwon EE (2021) Valorization of disposable COVID-19 mask through the thermo-chemical process. Chem Eng J 405:126658. https://doi.org/10.1016/j.cej.2020.126658

Kabakcı SB, Hacıbektaşoğlu Ş (2017) Catalytic pyrolysis of biomass. InTech

Kaufman L, Chasan E (2020) Cities wonder whether recycling counts as essential during the virus. Bloomberg green

Klemeš JJ, Van Fan Y, Tan RR, Jiang P (2020) Minimising the present and future plastic waste, energy and environmental footprints related to COVID-19. Renew Sustain Energy Rev. https://doi.org/10.1016/j.rser.2020.109883
Lee S, Yoshida K, Yoshikawa K (2015) Application of Waste Plastic Pyrolysis Oil in a Direct Injection Diesel Engine: For a Small Scale Non-Grid Electrification. Energy Environ Res 5:18-32. https://doi.org/10.5539/eer.v5n1p18

López A, de Marco I, Caballero BM et al (2011) Pyrolysis of municipal plastic wastes II: Influence of raw material composition under catalytic conditions. Waste Manag 31:973-1983. https://doi.org/10.1016/j.wasma n.2011.05.021

Ma C, Yu J, Wang B et al (2017) Catalytic pyrolysis of flame retarded high impact polystyrene over various solid acid catalysts. Fuel Process Technol 155:32-41. https://doi.org/10.1016/j.fuproc.2016.01.018

Mahbubani R (2020) US medical workers will need 3.5 billion face masks if the coronavirus reaches pandemic status. In: Bus. Insid. https://www.pulse .ng/bi/politics/us-medical-workers-will-need-35-billion-face-masks-if-thecoronavirus-reaches/r6wsxak

Majewsky M, Bitter H, Eiche E, Horn H (2016) Determination of microplastic polyethylene (PE) and polypropylene (PP ) in environmental samples using thermal analysis (TGA-DSC) ․ Sci Total Environ 568:507-511. https ://doi.org/10.1016/j.scitotenv.2016.06.017

Makarichi L, Jutidamrongphan W, Techato K (2018) The evolution of wasteto-energy incineration: A review. Renew Sustain Energy Rev 91:812-821. https://doi.org/10.1016/j.rser.2018.04.088

Mastral FJ, Esperanza E, Garciía P, Juste M (2002) Pyrolysis of high-density polyethylene in a fluidised bed reactor. Influence of the temperature and residence time. J Anal Appl Pyrolysis 63:1-15. https://doi.org/10.1016/ S0165-2370(01)00137-1

Miandad R, Barakat MA, Aburiazaiza AS et al (2016) Catalytic pyrolysis of plastic waste: A review. Process Saf Environ Prot 102:822-838. https://doi. org/10.1016/j.psep.2016.06.022

Miandad R, Rehan M, Barakat MA et al (2019) Catalytic pyrolysis of plastic waste: Moving toward pyrolysis based biorefineries. Front Energy Res 7:1-17. https://doi.org/10.3389/fenrg.2019.00027

Minnesota Department of Health (2020) Components of Personal Protective Equipment (PPE). In: Dep. Heal. https://www.health.state.mn.us/facilities/ patientsafety/infectioncontrol/ppe/comp/index.html

Miskolczi N, Bartha L, Deak G, Jover B (2004) Thermal degradation of municipal plastic waste for production of fuel-like hydrocarbons. Polym Degrad Stability 86:357-366. https://doi.org/10.1016/j.polymdegradstab.2004.04.025

Nam S, Slopek R, Wolf D et al (2016) Comparison of biodegradation of lowweight hydroentangled raw cotton nonwoven fabric and that of commonly used disposable nonwoven fabrics in aerobic Captina silt loam soil. Text Res J 86:155-166. https://doi.org/10.1177/0040517514551468

Nileshkumar KD, Jani RJ, Patel TM, Rathod GP (2015) Effect of Blend Ratio of Plastic Pyrolysis Oil and Diesel Fuel on the Performance of Single Cylinder Cl Engine. Int J Sci Technol Eng 1:195-203

Nirmal Ghosh OS, Gayathri S, Sudhakara P et al (2017) Nitrile Rubber Latex Blends: Preparation, Characterization and Applications. In: Rubber Nano Blends. Springer, Cham, pp 67-88

Patrício Silva AL, Prata JC, Walker TR et al (2020) Rethinking and optimising plastic waste management under COVID-19 pandemic: Policy solutions based on redesign and reduction of single-use plastics and personal protective equipment. Sci Total Environ 742:140565. https://doi. org/10.1016/j.scitotenv.2020.140565

Prata JC, Silva AL, Walker TR et al (2020) COVID-19 Pandemic Repercussions on the Use and Management of Plastics. Environ Sci Technol 54:7760-7765. https://doi.org/10.1021/acs.est.0c02178

Qin L, Han J, Zhao B et al (2018) Thermal degradation of medical plastic waste by in-situ FTIR, TG-MS and TG-GC/MS coupled analyses. J Anal Appl Pyrolysis 136:132-145. https://doi.org/10.1016/j.jaap.2018.10.012

Ratnasari DK, Nahil MA, Williams PT (2017) Catalytic pyrolysis of waste plastics using staged catalysis for production of gasoline range hydrocarbon oils. Elsevier B.V

Rehan M, Nizami AS, Shahzad K et al (2016) Environmental Effects Pyrolytic liquid fuel: A source of renewable electricity generation in Makkah Pyrolytic liquid fuel : A source of renewable electricity generation in Makkah. Energy Sources Part A Recover Util Environ Eff 38:2598-2603. https://doi. org/10.1080/15567036.2016.1153753

Rowan NJ, Laffey JG (2020a) Challenges and solutions for addressing critical shortage of supply chain for personal and protective equipment (PPE) arising from Coronavirus disease (COVID19) pandemic - Case study from the Republic of Ireland. Sci Total Environ 725:138532. https://doi. org/10.1016/j.scitotenv.2020.138532 
Rowan NJ, Laffey JG (2020b) Since January 2020 Elsevier has created a COVID19 resource centre with free information in English and Mandarin on the novel coronavirus COVID-19. The COVID-19 resource centre is hosted on Elsevier Connect, the company's public news and information. Sci Total Environ 725:138532

Rychlý J, Matisová-Rychlá L, Csomorová Ket al (2011) Non-isothermal thermogravimetry, differential scanning calorimetry and chemiluminescence in degradation of polyethylene, polypropylene, polystyrene and poly(methyl methacrylate). Polym Degrad Stab 96:1573-1581. https://doi. org/10.1016/j.polymdegradstab.2011.05.020

Sakata Y, Uddin MA, Muto A (1999) Degradation of polyethylene and polypropylene into fuel oil by using solid acid and non-acid catalysts. J Anal Appl Pyrolysis 51:135-155

Saptoadi H, Pratama NN (2015) Utilization of Plastics Waste Oil as Partial Substitute for Kerosene in Pressurized Cookstoves. Int J Environ Sci Dev 6:363-368. https://doi.org/10.7763/ijesd.2015.v6.619

Sarker M, Rashid MM, Molla M, Rahman MS (2012) A new technology proposed to recycle waste plastics into hydrocarbon fuel in USA. Int J Energy Environ 3:749-760

Schnurr RE, Alboiu V, Chaudhary M et al (2018) Reducing marine pollution from single-use plastics (SUPS): A review. Mar Pollut Bull 137:157-171. https://doi.org/10.1016/j.marpolbul.2018.10.001

Shah J, Jan MR (2015) Effect of polyethylene terephthalate on the catalytic pyrolysis of polystyrene: Investigation of the liquid products. J Taiwan Inst Chem Eng 51:96-102. https://doi.org/10.1016/j.jtice.2015.01.015

Sørum L, Grønli MG, Hustad JE (2005) Pyrolysis characteristics and kinetics of municipal solid waste. Trans Tianjin Univ 11:353-359
Steffan M (2020) Covid: PPE "could be recycled" with help of sunlight. In: BBC Wales Environ. Corresp. https://www.bbc.co.uk/ news/amp/uk-wales-55396511?fbclid=IwAR21ICRHexVeiFjZfz sq7oHfPGpDyxvsyMB6WIkAumFduDJI9AynKiuQh9w

Usubharatana P, Phungrassami H (2018) Carbon footprints of rubber products supply chains (Fresh latex to rubber glove). Appl Ecol Environ Res 16:1639-1657. https://doi.org/10.15666/aeer/1602_16391657

Wu SL, Kuo JH, Wey MY (2019) Thermal degradation of waste plastics in a twostage pyrolysis-catalysis reactor over core-shell type catalyst. J Anal Appl Pyrolysis 142:104641. https://doi.org/10.1016/j.jaap.2019.104641

You S, Sonne C, Ok YS (2020) COVID-19: Resource recovery from plastic waste against plastic pollution COVID-19: Resource recovery from plastic waste against plastic pollution. Cogent Environ Sci 6:1801220. https://doi. org/10.1080/23311843.2020.1801220

Zhang W, Shi Z, Zhang F et al (2013) Superhydrophobic and superoleophilic PVDF membranes for effective separation of water-in-oil emulsions with high flux. Adv Mater 25:2071-2076. https://doi.org/10.1002/adma.20120 4520

\section{Publisher's note}

Springer Nature remains neutral with regard to jurisdictional claims in published maps and institutional affiliations.

\section{Submit your manuscript to a SpringerOpen ${ }^{\circ}$ journal and benefit from:}

- Convenient online submission

- Rigorous peer review

- Open access: articles freely available online

- High visibility within the field

- Retaining the copyright to your article

Submit your next manuscript at $\boldsymbol{\nabla}$ springeropen.com 